\title{
Research on the Intelligent Teaching Model of Principles of Economics Course under the New Media
}

\author{
Huizhen Lai* \\ Guangzhou College of Commerce, Guangzhou 511363, Guangdong Province, China \\ *Corresponding author: Huizhen Lai, 326599389@qq.com
}

\begin{abstract}
With the rapid development of the internet, smart classroom has become the research interest of modern-day educational informatization. With Tiktok, WeChat, QQ, and other new media, the intelligent teaching model of "new media + education" has been derived. The research subject in this study is the economic and management undergraduate course, Principles of Economics. In regard to that, it is expounded based on the new media and an intelligent teaching model is designed in line with the development of colleges and universities in the new era to change the plight of the traditional classroom teaching model, stimulate learners' enthusiasm and interest in learning, as well as improve the teaching effect.
\end{abstract}

Keywords: New media; Principles of Economics; Intelligent teaching model

Publication date: August 2021; Online publication: August 30, 2021

\section{Introduction}

With the development of the internet, great changes have taken place in people's life, work, and studies. The integration of modern information technology into education has created many opportunities for the development of education. The emergence of new media technologies, such as Tiktok, micro-blog, WeChat, and QQ, has made learning personalized and intelligent. However, these changes have resulted in many issues among educators. Compared with learners from the traditional teaching model, the integration of information technology has made them very different in terms of their cognitive styles, learning attitudes, and learning habits. New media has brought about vibrancy to traditional classroom teaching. It improves learners' interest and enthusiasm in learning. In regard to college classroom teachings, new media technologies have solved the limitations of time and space, provided opportunities to obtain all kinds of knowledge and information needed in the process of learning, formed an open intelligent teaching system, as well as promoted the dissemination of knowledge and information in addition to the improvement of learners' absorption capability.

\section{New opportunities for the intelligent teaching model under the new media}

New media is a form of communication, in which digital technology is used to provide users with services and information. Computer network, wireless communication network, and other terminals (computers, mobile phones, and digital televisions) are the main transmission channels of new media. From the perspective of space, "new media" refers to the media corresponding to "traditional media"; digital compression and wireless network technologies are the pillars, in which their interactivity as well as their real-time and large capacities are used to cross geographical boundaries and finally achieving globalization. Compared with traditional classroom, smart classroom refers to an intelligent and personalized educational 
environment created by using information technologies, such as the internet, big data, and new media. With teachings through mobile phones, learners are able to prepare on their own, solve problems, and improve themselves through new media tools, such as WeChat, Tiktok, Jitter, intelligent teaching software, etc.

\subsection{Intelligent teaching model enhances learners' learning initiative and discourse power}

With the development and popularization of the new media, there are profound changes in the behavior patterns among learners. The proportion of obtaining information through new media channels is increasing day by day. Many learners would use the new media to search for information before their lessons. This strengthens learners' initiative and discourse power in the process of acquiring and sharing knowledge or information. In the traditional teaching model, learners would easily accept the fixed contents in their books, thus the space for independent change is very restricted. On the other hand, the new media provides a huge space for learners' personalized learning needs. They are able to obtain all kinds of information through the new media, and they have the opportunity to actively select different types of online learning resources according to their needs to assist in their understanding of the course contents and knowledge points. Autonomous learning enables learners to learn according to their acceptance and understanding of knowledge. Especially for learners with a relatively weak foundation, they can overcome their learning difficulties by repeatedly learning via watching videos and the help from teachers and other students. Learners with strong learning comprehension ability and quick to learn can appropriately speed up their learning progress and independently choose more challenging learning contents and links. In smart classrooms, the learners hold the main role, where they can independently choose and actively arrange their learning, time, and knowledge points.

\subsection{Smart classroom enhances the interaction and cooperation among learners}

In addition to obtaining information from new media platforms, learners can also share their learning experiences and feelings with their peers anytime and anywhere with these platforms. This helps in realizing "one-to-one" and "one to many" communication. With the traditional knowledge transfer via books, learners passively accept knowledge; however, the emergence of the new media breaks the one-way flow. The emergence of new media also allows information to be more transparent and provides learners with more opportunities to actively choose. In that way, learners would transform from their traditional way of passive acceptance to making active choices. The status of learners is strengthened along with an enhanced interaction between learners. Tiktok, micro-blog, WeChat, and other new media are introduced in classrooms to share current news and social issues. Along with new learning forms such as micro videos, hotspot analyses, and case discussions, students are actively involved in interaction, thinking, and analyzing problems through group discussion, self-exploration, interaction, and collaboration. Problems encountered by learners in the learning process can also be solved through these methods. Teachers have the role of being the observers and learning guides in smart classrooms by providing personalized guidance for various problems encountered by the learners, timely excavating links and contents with educational significance in the teaching process, and eventually achieving teaching guidance.

\subsection{Four changes with the intelligent teaching model}

First, it eliminates the traditional "full house" teaching method and changes it into a student-centered teaching method. Second, the roles of teachers and learners change, in which learners are the main focus throughout the learning process whereas teachers are the organizers, supporters, and instructors in learning. Third, compared with the traditional teaching model, the outstanding idea of smart classroom is to realize the change from "teaching before learning" to "learning before teaching." Fourth, the curriculum structure 
changes from the traditional way of "from classroom teaching to extracurricular homework" to "from extracurricular knowledge learning to classroom knowledge internalization." In view of the new media, the smart classroom aims to create innovative, interactive, and intelligent teaching environment through the new media, such as Jitter, micro-blog, WeChat, Tiktok, and QQ, in addition to form a perfect combination of classroom practice and intelligent teaching.

\section{Exploration and practice of Principles of Economics with the intelligent teaching model}

As a basic course, the Principles of Economics course focuses on the understanding and application in its teaching objectives, as well as organically combines classes, group discussions, and practical innovations. The combined class focuses on basic concepts, mastery of basic principles, explanation of practice and application, as well as professional analysis of practical application examples. Group discussions generally include practical application problems as the carrier and use both, in-class and out-of-class exploration or discussion. It increases the interest in learning, improves the ability of searching data, promotes the learning of division and cooperation, data sorting and induction, report writing, display and expression, etc. The basic form of learning that is advocated by research, applied teaching, and learning of basic courses is "active learning." Through the intelligent design of teaching contents and the personalized organization of the process of teaching, learners' enthusiasm for autonomous learning, thinking, expression, and innovation is improved.

\subsection{First task: Autonomous learning prior to class}

Learners are the emphasis in the learning process. In order to pique learners' interest in autonomous learning and maintain sufficient learning enthusiasm, teachers should clarify the learning objectives, priorities, and difficulties to learners at the beginning of the course. They should also make preparations prior to classes while using new media platforms, such as Tiktok, micro-blog, WeChat, QQ, etc., for exchange and discussion. When learners share their opinions or ask questions, teachers should provide necessary guidance, make summarization and induction, stimulate the enthusiasm of learners, as well as lay a good foundation for discussions in classrooms. They should also guide the learners to consult online teaching videos and file resources, formulate their own learning plans, complete the learning tasks that have been assigned prior to classes, and make full preparations for the progress of classroom activities.

\subsection{Second task: Organization of classroom activities}

Through classroom learning and practical participation, learners would be able to learn deeper and apply their knowledge. Teachers' guidance is closely related to their students' learning. In regard to the Principles of Economics course, the focus is on the students' learning, thus prior to classroom activities, it is important to adopt various flexible teaching methods based on the learners' thinking, psychological characteristics, and personality characteristics while implementing heuristic teaching, actively organizing forums, group discussions, and exchanges, as well as strengthening the teacher-student interaction along with studentstudent interaction. It is necessary to encourage learners to actively participate in teaching activities and build a "teacher + learner" learning community through team cooperation project-based discussion, group report performance, speeches, debates, and other ways. Other than that, the emphasis should also be on the complementarity of classroom teaching and practical teaching. Practicality should be highlighted along with promoting the three-dimensional teaching process. Previous course evaluation methods should be changed; the professional, hierarchical, common, and differential evaluation indicators should be redesigned; "student-oriented" learning should be fully reflected; the process management and online learning supervision should be strengthened; the process evaluation should be upheld; the feedback 
channels for learners should be unblocked; and a set of effective assessment, evaluation, and communication mechanism should be formed.

\subsection{Third task: Practice and exploration after class}

The links for practice can also be reviewed after classes through micro classroom and other learning software with the help of various platforms on the internet while making use of the learners' message area, regularly carry out online investigation, communicate with teachers on time, as well as provide feedbacks on the issues that have been encountered in the learning process. This task mainly refers to the extended learning in groups. Group members would reasonably complete the given tasks according to the practical project tasks of each section while demonstrating unity and cooperation. Learners should have a more clear and intuitive understanding along with a deeper grasp of theoretical knowledge and cases learned in addition to personally experience, collect data, think, summarize, record information, and write plans. The knowledge learned in classrooms should be applied in practice, key points should be clearly identified, and training in the form of observation, record, data collection, thinking, and discussion should be completed. It is required to have clear logic, prominent focus, and strong operability. In such autonomous activities, teachers need take up the role to guide and support, timely communicate, evaluate, and provide performance feedbacks to the learners, guide them to develop in a positive and effective direction, cultivate their innovative spirit of active exploration, as well as comprehensively improve their innovative ability.

\subsection{Fourth task: Diversified curriculum assessment and evaluation}

In the process of teaching, WeChat, QQ, Jitter, micro-blog, and other software are used to inform about learning tasks, share and display information, discuss problems, etc., in order to form a reverse classroom situation and improve the quality of the tasks. Flexible assessment methods have been adopted in the course assessment along with a combination of written examination opening, experimental operation, social investigation report, work design, and other assessment methods. According to the teaching requirements at different stages, the process assessment can be strengthened by means of discussions, questions, afterschool homework, cooperative group learning, classroom tests, and mid-term exams. In addition, the evaluation standards of each link should be formulated to ensure the accuracy of the process assessment and a diversified assessment and evaluation system should be established to scientifically evaluate learners' ability level.

\subsection{Fifth task: Optimize the score structure}

From focusing on knowledge memory assessment to knowledge application, practical skills, problemsolving skills, and innovation skills. In the course teaching, more emphasis is given to the teaching of knowledge points, case discussions, special debates, and practical activities. It does not only emphasize on international vision, but also industrial characteristics, regional social practice, connection between theoretical learning and social practice application, as well as the "wide caliber" teaching positioning. The structural proportion of peacetime scores and final examination scores should be optimized and set, and the process assessment should be highlighted.

\section{Conclusion}

The application of the intelligent teaching model in the Principles of Economics course has achieved good teaching results, stimulated learners' enthusiasm for autonomous learning, encouraged learners to focus more during classroom teachings, as well as reduced classroom slack and fatigue. However, there is still the issue of unreasonable class hour allocation. Smart classrooms need to be effective in consideration of 
in-class and extracurricular learning time. Therefore, it is necessary to make targeted and reasonable arrangements for class periods according to the actual situation, reduce the burden on learners, and reduce unnecessary loss of class periods. Special attention is required for teachers to consciously improve learners' self-control in the learning process with the internet platform, prompt learners' integrity issues in the learning process with the smart classroom and strengthen the supervision function through the analysis of learning data on the network teaching platform. In regard to smart classrooms, information feedback channels should also be timely established, including learners' message area, online survey feedbacks, forum discussions, etc., to solve the difficulties and doubts faced by learners in their learning process. The smart classroom, as a new teaching model, has given full play to the subjectivity and enthusiasm of the learners. In recent years, based on the teaching exploration of smart classroom, the Principles of Economics course has also implemented several new teaching concepts and methods in combination practical activities, classroom discussions, and group tasks in order to improve class participation and the frequency of response. It is expected that there would be continuous exploration and innovation in future teaching practices, thus providing experience and reference for other courses in the field of economics and management in regard to the intelligent teaching model.

\section{Disclosure statement}

The author declares that there is no conflict of interest.

\section{References}

[1] Wang S, 2020, Research on Mixed Teaching Mode of Ideological and Political Courses in Colleges and Universities Under the Background of New Media Era. Science, Education and Culture, (6).

[2] Zhang N, 2019, Research on the Wisdom Classroom Teaching Mode Under the Background of "Internet Plus Education". Jilin Business School, (2).

[3] Li D, 2020, Based on the Internet Plus Education, the Study of Wisdom Teaching Mode is Taken as an Example of "Financial Analysis" Curriculum Reform. Education and Teaching Forum, (1).

[4] Wu X, Zhou Y, 2016, Research on the Reform of Flipped Classroom Teaching Mode in Colleges and Universities Under New Media - Taking the Operation and Management of Agricultural Enterprises as an Example. Science and Education Forum, (6). 